\title{
A study on the present status of freelancers in speech-language rehabilitation
}

\author{
Myoung Soon Lee', Eun Kyoung Lee ${ }^{2}$, Hyun Park' \\ ${ }^{1}$ Department of Speech-Language Therapy, Sangji University, Wonju; ${ }^{2}$ Department of Speech-Language Therapy, Dongsin University, Naju, Korea
}

Purpose: Corona-19 Infectious Diseases temporarily closed the workplace of speech therapists or temporarily suspended the work. Therefore, we investigated the current status of speech therapists in order to enact freelancer support ordinances of each local government and to urge language rehabilitation workers to support them.

Methods: The study was conducted through an online Google questionnaire from May 20 to October 2, 2020 for language rehabilitation workers. The total number of participants was 2,055. The results were processed using SPSS 25.0 and descriptive statistics were performed.

Results: The results were processed using SPSS 25.0 and descriptive statistics were performed. First, private speech therapy centers $55.4 \%$, social welfare facilities $22.2 \%$, and hospitals $14.6 \%$ were in order of the type of workplace of Speech-language rehabilitation. Second, the types of work of Speech-language rehabilitation were professional freelance workers $43.0 \%$, contract workers of fixed pay $9.3 \%$, and contract workers of combination with fixed pay and rate system pay $6.9 \%$. Third, the insurance coverage of Speech-language rehabilitation were in the order of four major insurance $67.2 \%$, non-insured $20.3 \%$, and two major insurance $12.5 \%$. Forth, the number of workplaces of Speech-language rehabilitation were one workplaces $63.9 \%$, 2 workplaces $17.5 \%$, others $16 \%, 3$ workplaces $2.6 \%$.

Conclusions: Therefore, this study will be used as basic data for improving the treatment of speech therapists, and various efforts will be needed to expand the employment place that can guarantee the financial and employment stability from enactment of freelancer ordinances in each local government.

Keywords: Speech-language rehabilitation, Speech-language therapist, freelancer, Crona-19, contract workers, Rate-based salary

\section{INTRODUCTION}

Job hunting and job instability are reported through various media. In this reality, the standard employment type such as full-time employment due to employment instability gradually decreased and various irregular labor forms such as freelance or independent contractors and non-wage workers appeared. The number has increased in recent years, with the proportion of irregular labor forms in Korea as of 2018 the fifth highest in the OECD 35 countries [1,2]. Among the non-regular forms of labor, freelancers include non-wage workers, special workers, and one person business workers without employees, including all individuals who are not registered as business operators [3]. In the past, 'freelancer' was recognized as not a legal concept, nor a form of occupational group normally applied. However, the recent 'freelancer' is defined as a legal concept:

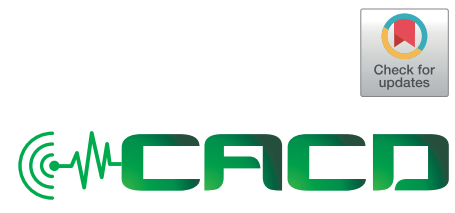

Received: November 29, 2020 Accepted: December 31, 2020

Correspondence:

Eun Kyoung Lee

Dept. of Speech-Language Therapy, Dongsin University, 67 Dongshindae-gil, Naju 58245, Korea

Tel: +82-061-330-3473

Fax: +82-061-330-3476

E-mail: eklee@dsu.ac.kr

This paper is a revision of a paper presented at the conference of the 21th Korean Speech-Language \& Hearing Association.

(C) 2020 The Korean Association of SpeechLanguage Pathologists

This is an Open Access article distributed under the terms of the Creative Commons Attribution NonCommercial License (https://creativecommons.org/ licenses/by-nc/4.0/) which permits unrestricted noncommercial use, distribution, and reproduction in any medium, provided the original work is properly cited. 
the Ordinance for the Protection and Support of Freelancer Rights in Seoul (2020.01.09). The term freelance means a person who works under a free contract without being applied to the Labor Relations Act, such as the Labor Standards Act, and does not belong to a certain company or organization regardless of the form of the contract. According to the Gyeonggi-do Freelancer Support Ordinance (2019.10.01), freelancer refers to a person who is not subject to the Labor Standards Act, the Employment Insurance Act, and the Occupational Safety and Health Act, regardless of the form of the contract, and who provides professional services without employees among business income earners subject to withholding under the Income Tax Act. The estimated number of freelancers in 2012 was about 656,000, and the ratio of their ages was the highest at $41 \%$ in their 20 s, followed by $28 \%$ in their 30 s. In the 2018 survey, the proportion of freelancers was estimated to be more than $16 \%$ of the population of economic activity, and it showed a tendency to expand around young people. Despite the increasing proportion of freelance workers, 54.6 percent of freelance workers, more than half of freelance workers, did not have regular and sustainable work in the 2018 Freelance Labor Environment Survey released by the Seoul Metropoli$\tan$ Government [4]. In the study of Lee Seung-ryul et al. [5], the freelance work regularity was $19.0 \%$ lower than that of selfemployed. In addition, the average monthly income of freelancers in 2018 was $1,529,000$, which is below the average monthly minimum wage of 157,000 in 2017 [4]. After the 2020 Corona virus-19, the government paid emergency disaster subsidies to the people to protect vulnerable people who were not protected by employment insurance. A total of 1.5 million won was paid for three months, 500,000 won per month for freelancers, special type workers, and non-wage workers with a certain income or less, whose income and sales decreased between March and April 2020 due to the Corona 19 incident. However, there have been cases where freelancers have abandoned applications for emergency disaster subsidies because it is difficult to prepare evidence documents for applying for the grant [6]. In addition, freelancers registered as dependents of parents or spouses with relatively high premium payments were excluded under the condition that the standard of disaster support was below $80 \%$ of the median income of health insurance premiums [7]. According to Lee et al. [8], freelancers are in fact in institutional blind spots because they demand sanctions on unfair contracts and human rights violations, health insurance and employment insurance, etc., even in institutional protections required for freelancers. As such, the number of people working in freelance form has increased significantly, but there are not many protection and support systems for freelance, and difficulties and problems in the support process are continuously pointed out. Nevertheless, there is a lack of research on freelance compared to studies on wage labor, self-employed or small business owners. And most studies on freelance are focused on the economic background of freelance jobs, or on the fields of broadcasting and art [9]. Corona-19 infections, which began in February 2020, are expected to continue in the long term, and the socioeconomic changes followed. In particular, the operators of the private language therapy center and the employed Speechlanguage rehabilitation were affected by the livelihood due to the suspension of services according to the guidelines of the Ministry of Health and Welfare. Speech-language rehabilitation companies in the form of contract workers have freelance characteristics. This study was conducted to urge each local government to enact freelance support ordinances and to ensure that Speech-language rehabilitation receive appropriate institutional support.

\section{METHODS}

This study was to investigate the current status of Speech-language rehabilitation and the ratio of freelance. For this purpose, the following methods were used.

\section{Questionnaire composition}

Examine the current status of speech-language rehabilitation and the ratio of freelancers, questionnaires were composed of two professors of language therapy who have more than 5 years of experience in Speech-language rehabilitation. The questionnaire consisted of 10 questions, 5 questions, and 5 questions about the general characteristics, which are presented in Table 1. The Crobach's Alpha coefficient of the questionnaire was 0.74 for general characteristics and 0.82 for Speech-language rehabilitation. The specific contents of the questionnaire are as follows.

\section{Participants}

This study was conducted with speech-language rehabilitation practitioners, and the survey was conducted from May 20 to October 2, 2020 through an online Google questionnaire. A total of 2,060 questionnaires were analyzed, excluding 10 questionnaires that included unfaithful answers or unfinished questions among the subjects who participated in the survey. 
Table 1. Questionnaire contents

\begin{tabular}{ll}
\hline Division & \multicolumn{1}{c}{ Item } \\
\hline Basic question & Local branch \\
& Age \\
& Career \\
& Education \\
& Type of work place \\
Key question & Type of working contract \\
& Type of insurance subscription \\
& Current monthly salary status for the last two months \\
& Number of work places \\
& Opinion on improvement \\
& 10 \\
\hline
\end{tabular}

Table 2. Participants' information

\begin{tabular}{llc}
\hline Category & & $\mathrm{N}(\%)$ \\
\hline Local branch & Kangwon branch & $63(3.0)$ \\
& Gwangju Honam branch & $233(11.3)$ \\
& Daegu Gyongbuk branch & $204(9.9)$ \\
& Daejeon Chungcheong branch & $210(10.2)$ \\
& Pusan Ulsan Gyeongnam branch & $380(18.4)$ \\
& Seoul branch & $386(18.7)$ \\
& Incheon Gyeonggi branch & $551(26.7)$ \\
Age & Jeju branch & $33(1.6)$ \\
& 20-29 years old & $825(40.0)$ \\
& 30-39 years old & $816(39.6)$ \\
& 40-49 years old & $306(14.9)$ \\
& 50-59 years old & $110(5.3)$ \\
& Over 60 years old & $3(0.1)$ \\
& 1-3 years & $616(28.3)$ \\
& 4-6 years & $584(29.9)$ \\
Education & 7-10 years & $443(20.2)$ \\
& Over 10years & $417(21.5)$ \\
& An university graduate & $155(7.5)$ \\
& Raduate school graduation or higher & $694(33.7)$ \\
\hline
\end{tabular}

The general information of the subjects is the same as Table 2 .

\section{Result processing}

This study was to investigate the status of freelance of Speechlanguage rehabilitation and the status of their work, and to do so, descriptive statistics were conducted using SPSS 25.0.
Table 3. Workplace type

\begin{tabular}{lc}
\hline Division & N (\%) \\
\hline Education and child care institutions & $190(9.2)$ \\
Private speech therapy center(Director) & $103(5)$ \\
Hospital & $301(14.6)$ \\
Private speech therapy center(speech therapist) & $1,141(55.4)$ \\
Social welfare facilities & $457(22.2)$ \\
Etc. & $82(4)$ \\
Total & 2,186 \\
\hline
\end{tabular}

\section{RESULTS}

\section{Workplace type}

The results of the questionnaires to find out the type of workplace of Speech-language rehabilitation were presented in Table 3 , and the question of workplace type was able to be answered in duplicate.

The total number of people who participated in the type of work place was 2,274, and 214 people responded in duplicate. The total number of people was about $9.0 \%$ for 2,060 people. Of the respondents who work in private Speech-language rehabilitation centers, 1,141 people accounted for $55.4 \%$ of the total. The next most people answered that 457 people $(22.2 \%)$ were working in social welfare facilities, and 301 people (14.6\%) answered that the third most working place type was hospitals.

Through the graph (Figure 1), it was found that the private Speech-language rehabilitation center was overwhelmingly high in the type of work of Speech-language rehabilitation.

\section{Form of work}

The results of the questionnaire items to investigate the working patterns of Speech-language rehabilitation workers were presented in Table 4, and the question of working patterns was able to be answered in duplicate.

The most common type of speech-language rehabilitation workers was professional freelancers, and $43.0 \%$ of 2,195 respondents were professional freelancers. There were 151 contract workers who combined full-time and ratio system, and 206 contract workers with fixed-level contracts.The graph of this is shown (Figure 2), and the ratio of full-time and professional freelancers is very high.

\section{Insurance subscription status}

The results of the questionnaire items to investigate the status 


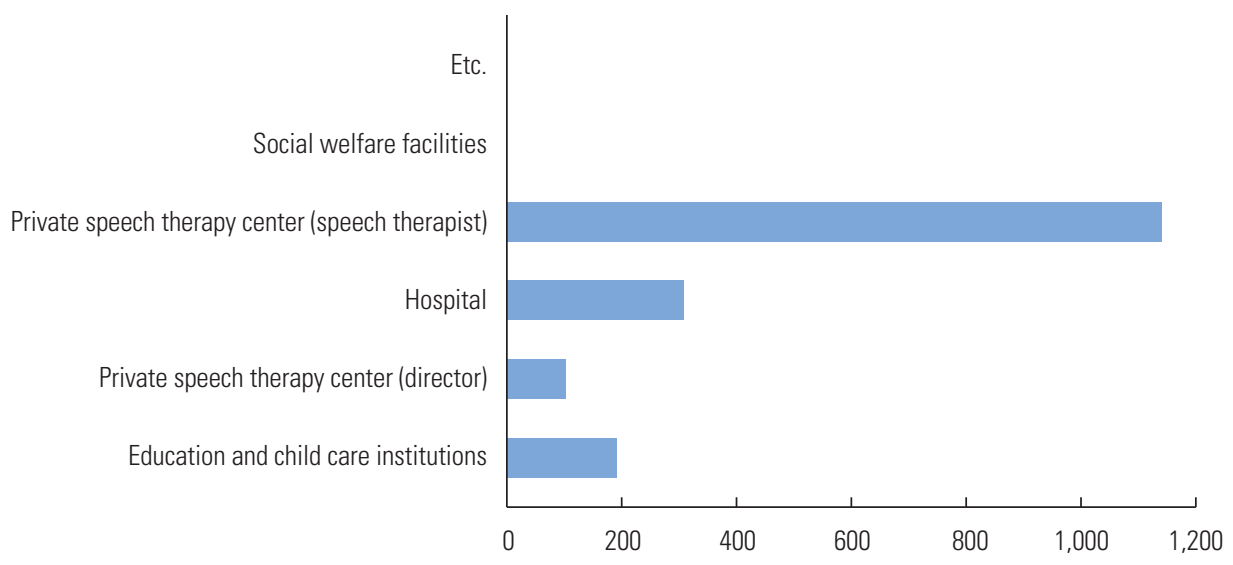

Figure 1. Workplace type.

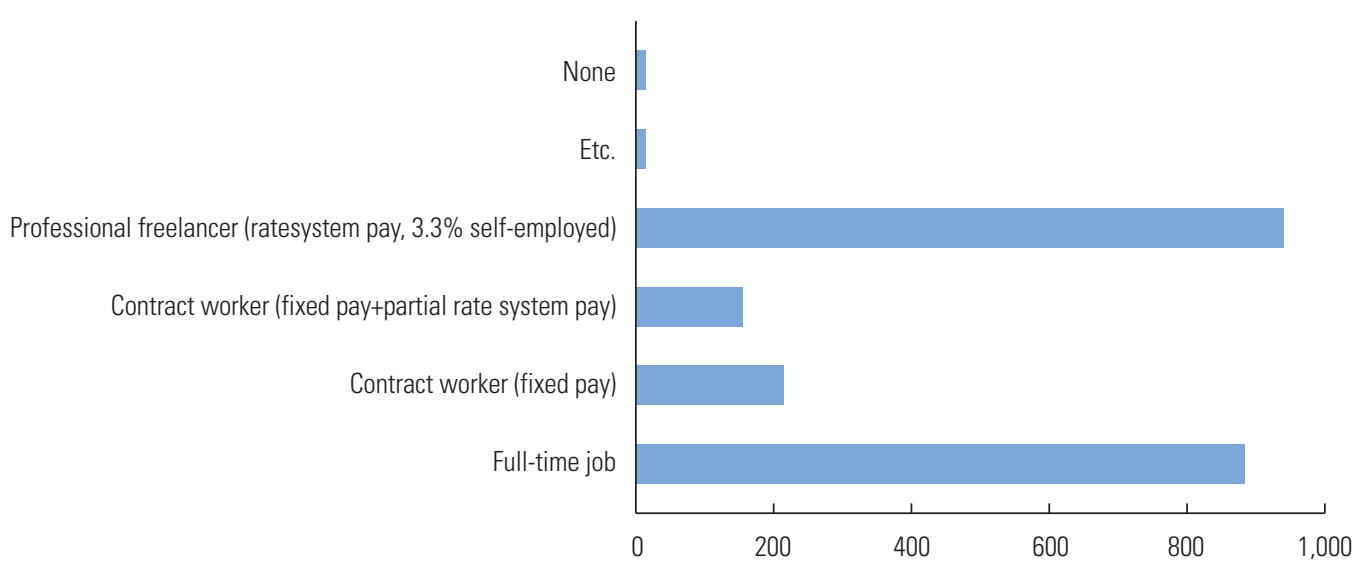

Figure 2. Form of work.

Table 4. Work contract form

\begin{tabular}{lc}
\hline Division & $\mathrm{N}(\%)$ \\
\hline Full-time job & $885(40.3)$ \\
Contract worker (fixed pay) & $206(9.3)$ \\
Contract worker (fixed pay+partial rate system pay) & $151(6.9)$ \\
Professional freelancer (rate system pay, 3.3\% Self-employed) & $943(43)$ \\
Etc. & $6(0.3)$ \\
None & $4(0.2)$ \\
Toal & 2,195 \\
\hline
\end{tabular}

of insurance coverage of Speech-language rehabilitation companies were presented in Table 5.

The results of the insurance status of Speech-language rehabilitation were the highest among 1,384 respondents who had four major insurance(Health Insurance, Industrial Accident Insurance, Employment Insurance, National Pension) policies, followed by 419 and $20.3 \%$ who did not have insurance. The number of the two major insurance(employment
Table 5. Insurance subscription status

\begin{tabular}{lc}
\hline Division & $\mathrm{N}(\%)$ \\
\hline $\begin{array}{l}\text { Four major insurances (Health Insurance, Industrial Accident } \\
\text { Insurance, Employment Insurance, National Pension) }\end{array}$ & 1,384 (67.2) \\
$\begin{array}{l}\text { 2 major insurance (employment insurance, industrial } \\
\text { accident insurance) }\end{array}$ & $257(12.5)$ \\
Uninsured & $419(20.3)$ \\
Toal & 2,060 \\
\hline
\end{tabular}

insurance, industrial accident insurance) policies was 257 and $12.5 \%$, and the results were analyzed through the graph (Figue 3). Graphical rolls showed that the number of non-insured persons was 419 , which was $20.3 \%$, which is much higher than the two major insurance subscribers.

\section{Number of places of work}

Table 6 shows the results of the survey to find out the number of workplaces working at the same time per speech-language 


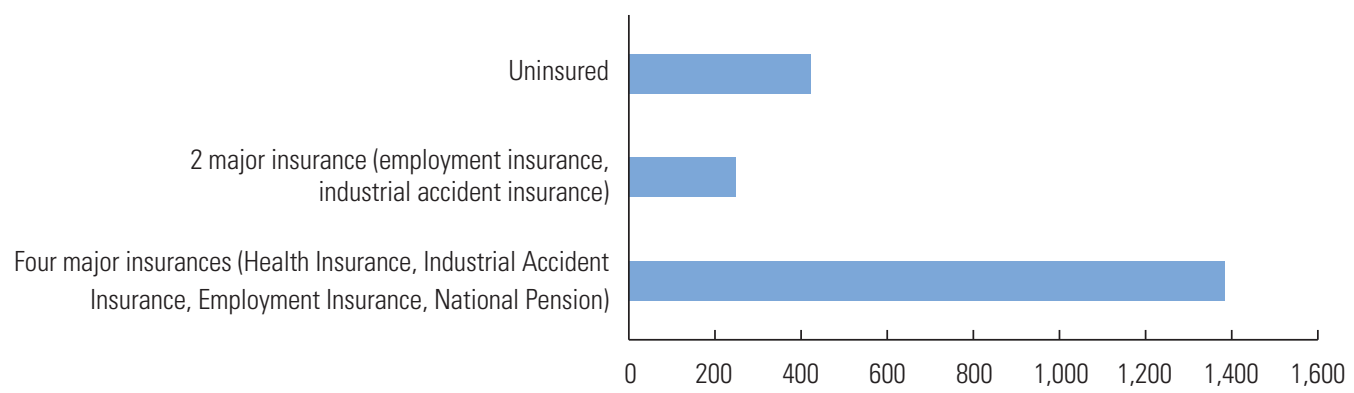

Figure 3. Insurance subscription status.

Table 6. Number of places of work

\begin{tabular}{lc}
\hline Division & $\mathrm{N}(\%)$ \\
\hline 1 & $1,316(63.9)$ \\
2 & $360(17.5)$ \\
$3 \leq$ & $54(2.6)$ \\
Etc. & $330(16)$ \\
Total & 2,060 \\
\hline
\end{tabular}

rehabilitation worker.

The number of people working in one workplace among Speech-language rehabilitation was the highest with 1,316 people, and the number of people working in two workplaces was 359 , accounting for $17.5 \%$ of the total respondents (Figure 4 ).

\section{DISCUSSION}

Policy changes considering the changing economic structure and the changing speed and aspect of the employment environment are urgent. Korea has adopted a labor flexibility strategy that favors irregular employment, which is easy to dismiss, due to economic uncertainty and economic downturn after the financial crisis. In addition, the transition from manufacturing to service economy has been made, and employment forms that are remarkably different from traditional industrialization have emerged, and the foundation of social insurance, which was maintained in regular employment relations, has begun to shake. Moreover, as economic activity has shrunk due to the recent Corona 19 crisis, the world economy is expected to have the most serious economic downturn since the Great Depression [10]. The spread of corona 19 and the subsequent closure of the economy have limited economic activities, and the employment market situation has become very weak not only in Korea but also in the world. This change in the employment market has also brought about a great change in the employment environment of

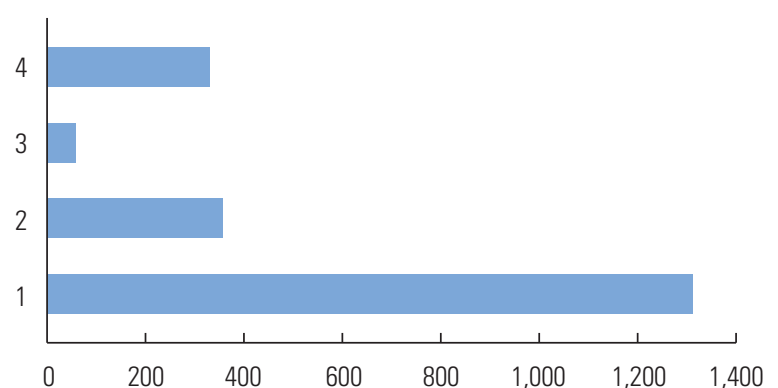

Figure 4. Number of places of work.

Speech-language rehabilitation.

The results of this study are summarized as follows. First, private Speech-language rehabilitation centers (1,141, 55.4\%), social welfare facilities (457, 22.2\%), and hospitals (301, 14.6\%) were in the order of the type of workplace of speech-language rehabilitation. Second, the types of work of Speech-language rehabilitation were professional freelance workers (943, $45.9 \%$ ), fixed-level contract workers (206, 10.0\%), and contract workers (149, $7.3 \%)$ who combined fixed-level and ratio system. Third, the four major insurance policies $(1,384,67.2 \%)$, non-insured (419, 20.3\%), and two major insurance policies $(257,12.5 \%)$ were in the order of the status of the Speech-language rehabilitation' insurance coverage. Fourth, the number of workplaces of Speech-language rehabilitation was 1,316, $63.9 \%, 2$ workplaces $(360,17.5 \%)$, others $(330,16 \%, 3$ work places $(54,2.6 \%)$.

In the process of analyzing the research, even if full-time workers are employed, even if they are covered by the rate system and the four major insurance policies, the salary is not fixed. Since the ratio-based pay form of speech-language rehabilitation is very similar to the freelance pay tendency, 1,298 (63.1\%) can be said to be freelance when it is considered that the actual freelance means both professional freelance and contract. There is also a risk that 419 speech-language rehabilitation who are not insured (20.3\%) are identified, which 
could be excluded from employment proof and employment stability.

Freelancers have long been fixed into groups that have characteristics that are distinguished from existing employment forms. When they are called freelancers, they are placed in labor conditions and poor labor conditions, and are not protected by the social safety net [11]. Oh Jae Ho [3] said that freelancers suffer from several common difficulties due to unfair transactions: First, they do not receive the remuneration or receive only a part of the remuneration. Freelancers are not recognized as workers, so if the company does not receive compensation, there is no relief requesting agency, and it is difficult to compete with the company, so it may be abandoned. According to a study by the Gyeonggi Provincial Council in 2019, two out of ten freelancers in the province were not paid or on time, and 50\% of them were given up on remuneration. They also said that they would require additional work or over responsibility that was not set at the time of the contract. Second, freelancers don't get social security. The shorter the employer's career, the more often the four major insurances were not covered. Third, freelancers are uncertain about the future or anxiety is caused by a gap in income. Freelancers often rely on human networks to get work, so it is difficult to have the continuity of work with personal efforts alone. Nam \& Kim [12] argues that a single-person company such as freelancer in a platform economy is "the last choice to work autonomously" and "the risk of self-exploitation" is" and "can escape from employment problems but stay in the income lower class due to low productivity. "This is a good expression of the difficult reality of freelance as the concept of a one-person company. The International Labor Organization (ILO, 2006) considers the form of labor such as freelancer as a representative example of 'work that needs protection'

Despite these difficulties in the form of freelance employment, the social stability network in the labor market centered on wage workers is not able to keep up with this, and there is a blind spot where they do not receive help despite the need for social protection for freelance workers [13]. There is a limit to appealing only to the ethical aspects of the organization to which the worker belongs in order to protect the freelancer. In order to protect freelancers and create good jobs, institutional and policy improvement directions must be sought.

In foreign cases, the Freelancer Protection Act of New York City in the United States is one of the good job models in the city. On April 15, 2017, New York City enacted the 'Freelance
Woker Right', which includes written contracts, timely payment of wages, rights to sue employers, legal services, and freedom from retaliation. The purpose of this law is that the rights of workers should be guaranteed regardless of the type of labor employment. The United States or the United Kingdom also pays freelancers retirement pensions and provides health insurance, and several associations in the United Kingdom deduct certain amounts of freelancer revenues as a mutual aid [10]. Now, the Korean government should not focus on employment policies to lower the unemployment rate, but should prepare policy plans based on 'structural changes in the labor market' and establish a social safety net so that nonregular workers such as freelancers should not be excluded from the labor market.

On the other hand, the type of freelance employment can affect job satisfaction. According to Yu [14], the type of employment contract can be a major factor affecting job satisfaction, and the freelance type shows the lowest job satisfaction. Jobs are not simply solved alone, but consist of tasks, interaction with responsibilities, incentive system and compensation. Extrinsic factors affecting job satisfaction include appropriate compensation for job, welfare, and working environment [15]. In this regard, the rapid increase in freelance employment of speeh thearpists can lead to low job satisfaction of speech-language rehabilitation. Park et al. [16] said that the current treatment of speech-language rehabilitation is a factor that increases the stress on the job physically, psychologically and financially and lowers the job satisfaction. The low job satisfaction of speech-language rehabilitation does not end in personal terms and can be done with low quality language therapy services.

Therefore, based on the results of this study, it is suggested to improve the treatment of Speech-language rehabilitation and to establish and support freelance ordinances for each local government. In addition, various efforts are needed to expand the employment place so that the employment stability of Speech-language rehabilitation can be guaranteed in the future.

\section{REFERENCES}

1. Statistics Korea. 2018 Economic Activity Population Survey. 2020.

2. OECD (2020). OECD ECONOMIC SURVEYS: KOREA 2020. https://www.oecd.org/economy/surveys/korea-2020-OECDeconomic-survey-overview.pdf.

3. Oh JH. New labor livelihood and freelancers, monthly public policy. 2019;164:57-61. 
4. Seoul Metropolitan Government. Survey on the status of freelance of labor research in Seoul. 2018.

5. Lee SY. Labor and Risk of Freelancers. Korea Labor Research Institute. 2013.

6. Kim JM. Research of freelance dancers's career path (Master's thesis). Chung-Ang University, Seoul. 2020.

7. Jeon Buk Newspaper Special worker. The freelance disaster grant is not alienated, internet newspaper. 2020.

8. Lee SY, Park KJ, Kim GH. A qualitative study of young freelancers' experience of work and social protection system in south korea. Journal of Critical Social Policy. 2019;64:181-239.

9. Jang JI. An analysis of sustainability of cooperatives as an economic organization for freelancers and its policy implications, Journal of Labor Policy Research. 2019;19:29-58.

10. Kim HJ. Corona 19's three major issues related to the labor market and countermeasures. Issue paper. 2020;13:1-15

11. Kim JJ. Implications for direct employment and employment model improvement of tbs traffic broadcasting freelance. Issue paper. 2018;4:1-18.

12. Nam YS, Kim IS. Die kultur der neuen arbeitsplätze in deutschland in der zeit der vierten industriellen revolution. Deutsch als Fremdsprache in Korea. 2017;41:105-124.

13. Lee RL. A study on the types of Transition Path of Labor Market of youths : focus on precariousness of work. (Master's thesis), Catholic University, Seoul. 2019.

14. Yu MY. Job satisfaction level per employment contract type; centering on demographic group comparison (Master's thesis), Inha University, Incheon. 2010.

15. Jung KH. The effects of empowering leadership on job satisfaction and organizational commitment (Doctoral dissertation), Sungkyunkwan University, Seoul. 2011.

16. Park H, Lee MS, Park CH. Job stress factors and turnover of registered voucher language pathologists. Journal of Speech-Langage and Hearing Disorders. 2013;22:227-250. 